\title{
$\mathrm{AP}$ 의 채널 설정 및 밀집도에 따른 무선 랜의 전송 속도에 관한 실험
}

\section{Experiment of the Throughput of WLAN according to Channelling and Density of AP}

\author{
심 용 섭 ${ }^{* \star *} \cdot$ 전 상 봉* $\cdot$ 박 승 근* \\ Yong-Sup Shim**** Sang-Bong Jeon* · Seung-Keun Park* \\ 요 약
}

본 논문에서는 $2.4 \mathrm{GHz}$ 대역을 사용하는 802.11 기반의 무선 랜 상호간 전파 간섭에 따른 전송 속도에 관한 실험이다. 최근, 휴대용 노트북과 스마트폰의 활성화로 무선 랜 밀집 공간이 증가함에 따라, 이 공간에서 설치된 무선 랜 간에 전파 간섭으로 인한 전송 속도 저하가 우려되고 있다. 이와 관련하여 본 논문은 다수 무선 랜에 설치된 시나리오를 구성하여 채널 조합에 따른 전송 속도를 측정하여 보다 효율적인 채널 조합을 제시하였고, 설치된 $\mathrm{AP}$ 의 수에 따른 전송 속도를 측정하여 설치 $\mathrm{AP}$ 의 수와 전송 속도와의 관계를 도출하였다. 측정 결과, 보다 효율적인 채널 조합으로 $1,5,9,13$ 을 제시하며, 설치 $\mathrm{AP}$ 의 밀집도가 증가할수록 전송 속도는 감소하는 것으로 나타났다.

\section{Abstract}

This paper is about the experiment which is throughput of WLANs based on 802.11 due to interference each other. Recently, WLAN has been increased due to generalization of smart-phone and potable notebook. Therefore, the decrease of throughput because of interference between WLANs is expected. In regard of this, the throughput of WLANs according to channelling is measured in order to figure out efficient channelling and the throughput of WLANs according to the number of AP was measured in order to get relation between number of AP and throughput. Then, more efficint channelling of $1,5,9,13$ is suggested and the throughput of WLAN is decreased as increasing of number of AP.

Key words : Radio Interference, WLAN, Channelling, Throughput

\section{I. 서 론}

전 세계적으로 유비쿼터스 시대를 넘어 스마트 시대 구현을 위한 다양한 무선 서비스가 개발되어 상용화되고 있으며, 이러한 서비스의 실현을 위해 고속의 정보 전송을 위한 광대역 특성을 갖는 최첨
단 IT 및 멀티미디어 기기들의 사용이 증가하고 있 는 추세이담] 이러한 추세는 새로운 주파수에 대한 수요를 증가시켜 한정된 주파수 자원의 고갈문제에 직면하게 되고, 이 문제를 해결하기 위해 주파수 효 율성을 극대화하는 동시에 상호간에 간섭을 최소화 하는 노력이 절실히 요구되고 있다. 최근에는, 무선 랜

\footnotetext{
「본 연구는 방송통신위원회의 ETRI 연구개발 지원사업의 연구결과로 수행되었음(KCA-2011-08921-01303).」

*한국전자통신연구원 스펙트럼공학팀(Spectrum Engineering Team, Electronics and Telecommunications Research Institute)

**공주대학교 정보통신공학과(Dept. of Information \& Communication Engineering, Kongju National University)

- Manuscript received December 16, 2011 ; February 3, 2012 ; March 19, 2012. (ID No. 20111216-162)

- Corresponding Author : Yong-Sup Shim (e-mail : besttla@kongju.ac.kr)
} 
을 사용하는 노트북이 증가하고, 와이파이를 탑재한 스마트폰이 널리 사용되면서 다수의 무선 랜이 설치 된 밀집 공간이 형성됨에 따라 이 곳에서의 동일 채 널 및 인접 채널 간섭 현상이 우려되고 있다 ${ }^{[2] .[3] . ~}$

지금까지 수행된 무선 랜 관련 간섭 연구는 무선 랜과 $\mathrm{RF}$ (Radio Frequency) 전구와의 간섭 ${ }^{[4]}$, 무선 랜 과 무선 랜 간의 간섭에 관한 연구 ${ }^{[5] \cdot[6]}$ 등이 있으며, 특히 무선 랜 상호 간의 간섭 연구를 살펴보면 단지 2대의 무선 랜 $\mathrm{AP}$ (Access Point)에 대한 것으로 AP A 와 $\mathrm{B}$ 간의 간섭만을 분석하였다. 따라서 현재 무선 랜이 밀집한 공간에서 현저한 전송 속도 저하 현상 이 발생함 ${ }^{[7]}$ 을 감안할 때 다수의 무선 랜이 존재하는 공간에 대한 상호 간섭 연구가 요구되고 있다.

이와 관련하여 본 논문은 무선 랜이 밀집된 공간 을 구성하여 설치된 $\mathrm{AP}$ 에 설정된 채널 조합에 따른 전송 속도를 측정하였으며, 한정된 공간에 설치된 $\mathrm{AP}$ 의 수를 변화시켜 이에 따른 전송 속도를 측정하 였다. 첫 번째 실험을 통해 최대의 전송 속도를 나타 내는 최적 채널 조합을 도출하였고, 두 번째 실험을 통해 $\mathrm{AP}$ 의 밀집도에 따른 전송 속도와의 관계를 확 인할 수 있었다.

\section{II. 국내 밀집 공간 측정 및 효율적 채널 조합 제시}

\section{2-1 국내 무선 랜 밀집 공간의 전파 환경 측정}

국내에서 대중들이 많이 모이는 지역으로 대규모 무선 랜 사용자가 예상되는 $\mathrm{A}, \mathrm{B}, \mathrm{C}$ 지역을 선정하 여 이곳의 무선 랜 전파 환경을 측정하였다. 측정 장 비로는 무선 랜의 전파 환경 측정에 널리 사용되는 $\mathrm{S} / \mathrm{W}$ 인 Network-Stumbler ${ }^{[8]}$ 가 설치된 노트북을 이용 하여 측정 지점에 검색되는 무선 랜의 수신 파워, 설 정 채널, $\operatorname{SSID}($ Service Set IDentifier) 등에 대한 정보 를 수집하였다. 그림 1 은 $\mathrm{A}, \mathrm{B}, \mathrm{C}$ 세 측정 지점 가운 데 가장 많은 수의 무선 랜 $\mathrm{AP}$ 가 검색된 $\mathrm{A}$ 지역의 전파 환경을 나타낸다.

그림 1 의 무선 랜 전파 환경 측정 결과, 총 224개 의 $\mathrm{AP}$ 가 검색되었으며, 이 중에서 모든 $\mathrm{AP}$ 가 간섭 을 미치는 것은 아니며 측정 지점에서 수신된 파워 에 따라서 간섭의 정도가 결정된다. 따라서 무선 랜 의 최소 수신 파워가 $-76 \mathrm{dBm}$ 임을 감안했을 때, 이

\begin{tabular}{|c|c|c|c|c|c|}
\hline \multicolumn{4}{|c|}{ (4) 2010111915162_료엑스 } & \multicolumn{2}{|c|}{$-\square x$} \\
\hline MAC & SSID & Chan & Type & Signal+ & (1) \\
\hline$($ 06300D 4FB2AD & $T$ wifi zone_secure & 11 & AP & -61 & \\
\hline (9) $02300 \mathrm{D} 4 \mathrm{FB} 2 \mathrm{AD}$ & & 11 & $\mathrm{AP}$ & -61 & \\
\hline 0025A.6A5813A & QOOKnSHOWbasic & 11 & $\mathrm{AP}$ & -59 & \\
\hline $00300 D$ 4FB2AD & $T$ wifi zone & 11 & AP & -61 & \\
\hline 063000 4FB $2 E 9$ & T wifi zone_secure & 6 & $\mathrm{AP}$ & -70 & \\
\hline $02300 \mathrm{D} 4 \mathrm{FB} 2 \mathrm{E} 9$ & & 6 & AP & -71 & \\
\hline $081075058 \mathrm{DBE}$ & NESCAMIP & 5 & AP & -61 & \\
\hline 0025AGA56ABO & QOOKnSHOWbasic & 1 & AP & -55 & \\
\hline ECFE $58 F E 7076$ & hpsetup & 1 & Peer & -61 & \\
\hline 0022756CA.65E & spmi00 & 1 & $\mathrm{AP}$ & -56 & \\
\hline () 0025A6A58139 & QOOKnSHOW & 11 & $\mathrm{AP}$ & -60 & \\
\hline $00303 F 510171$ & john-PC & 13 & AP & -71 & \\
\hline 0025A6A58138 & NESPOT & 11 & $\mathrm{AP}$ & -57 & \\
\hline $7828030 F 58 D 4$ & anygate & 1 & $\mathrm{AP}$ & -53 & \\
\hline 0025А.6А.0С688 & NESPOT & 1 & AP & -70 & \\
\hline $00265 A 461378$ & coex-skbb-56 & 7 & AP & -71 & $\equiv$ \\
\hline 0025A.6A.0E596 & NESPOT & 6 & $\mathrm{AP}$ & -61 & \\
\hline (e) 06300D54B0F7 & $T$ wifi zone_secure & 11 & AP & -61 & \\
\hline 0021299DССво & DDS-D12 & 2 & AP & -66 & \\
\hline 00300D54B0F7 & $T$ wifi zone & 11 & AP & -61 & \\
\hline 0025А.6АОС68А & QOOKnSHOWbasic & 1 & $\mathrm{AP}$ & -58 & \\
\hline 00089F6ECE 29 & plantynet & 6 & AP & -55 & \\
\hline () $06300 \mathrm{D} 4 \mathrm{FB} 2 \mathrm{C7}$ & T wifi zone_secure & 6 & $\mathrm{AP}$ & -58 & \\
\hline (P) 023000 4FB 2 C7 & & 6 & AP & -60 & $\sim$ \\
\hline IIII & & & & $\geq$ & \\
\hline
\end{tabular}

그림 1. 무선 랜 밀집 공간의 전파 환경(A 지역)

Fig. 1. Radio environment in space of multiple WLAN (region A).

표 1. AP에 설정된 채널 분포

Table 1. Selected channel distribution of AP.

\begin{tabular}{|c|c|c|c|c|c|}
\hline \multirow{2}{*}{ 측정 지점 } & \multicolumn{5}{|c|}{ 채널 별 $\mathrm{AP}$ 의 수 } \\
\cline { 2 - 6 } & 1 & 6 & 11 & 기타 & 총 \\
\hline $\mathrm{A}$ & 74 & 63 & 52 & 35 & 224 \\
\hline $\mathrm{B}$ & 7 & 20 & 14 & 6 & 47 \\
\hline $\mathrm{C}$ & 29 & 9 & 11 & 24 & 72 \\
\hline
\end{tabular}

보다 높은 $-60 \mathrm{dBm}$ 이상의 수신 파워를 갖는 $\mathrm{AP}$ 의 수가 78 개로, 이는 무선 랜 상호 간에 간섭이 발생할 수 있는 충분한 숫자로 생각된다. 또한, $\mathrm{AP}$ 의 송신 파워는 최대 $20 \mathrm{dBm}$ 으로 측정된 수신 파워에 따라 서 불과 수 $m$ 의 이격 거리를 두고 $\mathrm{AP}$ 가 설치된 경우 도 있음을 유추할 수 있다.

또한, 측정 지점 $\mathrm{A}, \mathrm{B}, \mathrm{C}$ 지점에서 측정된 $\mathrm{AP}$ 의 채널 별 분포를 표 1 에 나타내었다.

표 1 에서 보듯이 $\mathrm{A}, \mathrm{B}, \mathrm{C}$ 지역에서 총 13 개의 가 용 채널 중 $1,6,11$ 번의 3 개 채널을 사용하는 $\mathrm{AP}$ 의 수가 나머지 10 개 채널을 사용하는 $\mathrm{AP}$ 의 수보다 지 역별로 2 7배 정도 많게 검색되었다. 이와 같은 채 널 사용은 설치된 $\mathrm{AP}$ 의 대다수를 차지하는 통신사 업자들의 채널 설정 정책을 반영하는 것으로 동일 채널 사용에 따른 주파수 중첩 현상을 심화시켜 결 국 무선 랜의 심각한 전송 속도 저하를 초래하는 것 
THE JOURNAL OF KOREAN INSTITUTE OF ELECTROMAGNETIC ENGINEERING AND SCIENCE. vol. 23, no. 5, May 2012.

표 2. 무선 랜의 채널 및 중심 주파수

Table 2. Channel and center frequency of WLAN.

\begin{tabular}{|c|c|c|}
\hline $\begin{array}{c}\text { 주파수 } \\
\text { 대역 }\end{array}$ & 채널 번호 & 중심 주파수(MHz) \\
\hline \multirow{4}{*}{} & 1 & 2,412 \\
\cline { 2 - 3 } & 2 & 2,417 \\
\cline { 2 - 3 } & 3 & 2,422 \\
\cline { 2 - 3 } & 4 & 2,427 \\
\cline { 2 - 3 } $2,400 \sim$ & 5 & 2,432 \\
\cline { 2 - 3 } $2,483.5$ & 6 & 2,437 \\
\cline { 2 - 3 } $\mathrm{MHz}$ & 7 & 2,442 \\
\cline { 2 - 3 } & 8 & 2,447 \\
\cline { 2 - 3 } & 9 & 2,452 \\
\cline { 2 - 3 } & 10 & 2,457 \\
\cline { 2 - 3 } & 11 & 2,462 \\
\cline { 2 - 3 } & 12 & 2,467 \\
\cline { 2 - 3 } & 13 & 2,472 \\
\hline
\end{tabular}

으로 사료된다.

\section{2-2 효율적인 채널 조합 제시}

$2.4 \mathrm{GHz}$ 대역을 사용하는 국내 무선 랜 채널 및 주파수는 표 2와 같이 $2,400 \sim 2,483.5 \mathrm{MHz}$ 대역에 각 채널당 $22 \mathrm{MHz}$ 의 대역폭을 갖는 13 개의 채널로 할당되어 있다.

지금까지 국내 무선 랜 밀집 공간의 전파 환경 측 정 결과, $1,6,11$ 의 채널을 집중적으로 선택하여 사 용하는 것으로 나타났다. 이는 표 2에서 나타낸 무 선 랜의 총 주파수 대역에서 $22 \mathrm{MHz}$ 의 대역폭을 갖 는 각 채널 중에서 중첩을 피할 수 있는 채널이 그림 2 와 같이 $1,6,11$ 번임에 따라서 무선 랜의 채널 설정 이 이루어진 것으로 보인다.

기존의 $1,6,11$ 번의 채널 조합에서 그림 3 과 같이 한 채널을 더 확장하여 $1,5,9,13$ 의 채널 조합을 선

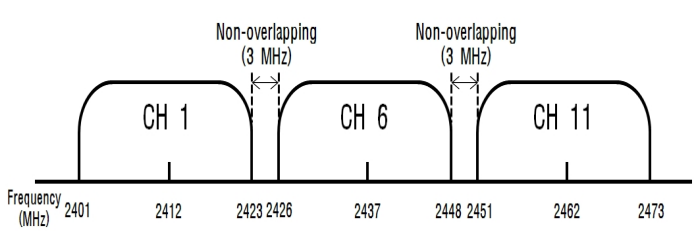

그림 2. $1,6,11$ 번의 채널 조합

Fig. 2. Channelling of $1,6,11$.

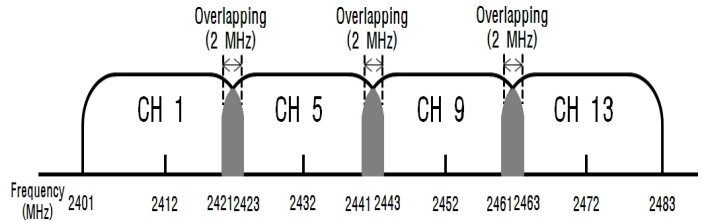

그림 3. 1, 5, 9. 13번의 채널 조합

Fig. 3. Channelling of $1,5,9,13$.

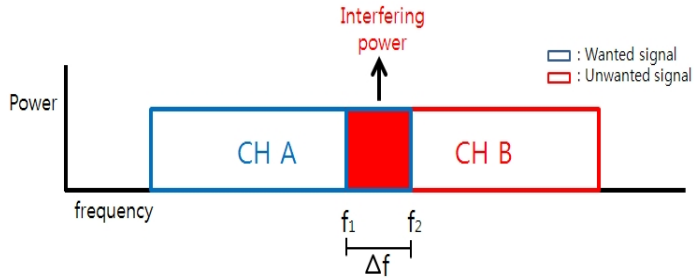

그림 4. 간섭 전력

Fig. 4. Interfering power.

택하였을 경우, 각 채널 간에 $2 \mathrm{MHz}$ 의 중첩을 허용 하더라도 한 채널을 추가로 확장함에 따라 총 전송 속도의 상승을 기대할 수 있다.

\section{2-3 간섭 전력과 전송 속도와의 관계}

채널 $\mathrm{A}$ 를 사용하는 단말기에 수신된 인접 채널 $\mathrm{B}$ 의 간섭 전력은 그림 4 와 같이 채널 $\mathrm{A}$ 와 $\mathrm{B}$ 중첩 대 역폭으로 표현할 수 있다.

간섭 전력의 크기 $\left(P_{I}\right)$ 를 계산하기 위해서는 먼저, 식 (1)과 같이 대역폭 $(B)$ 를 갖는 채널의 전력 $\left(P_{T}\right)$ 을 1 $\mathrm{Hz}$ 의 전력으로 정규화한 후, 중첩 대역폭 $(\triangle f)$ 을 곱 해서 구할 수 있다.

$$
P_{I}=\left(P_{T}-10 \log _{10}(B / 1(\mathrm{~Hz})) \times \Delta \mathrm{f}\right.
$$

이같이 계산된 간섭 전력은 식 (2)에서 신호대잡 음비 $(S / N)$ 의 잡음 전력에 합산되어 결국 전송 속도 $(C)$ 를 감소시킨다.

$$
C=B \cdot \log _{2}(1+S / N)
$$

\section{III. 전송 속도 비교 실험}

3-1 채널 조합별 전송 속도 측정

먼저, 채널 조합에 따른 전송 속도를 비교하기 위 해 외부로부터 유입되는 신호를 차단한 전자파 반무 
표 3. 전자파 반무반사실 실험

Table 3. Experiment in semi-anechoic chamber.

\begin{tabular}{|c|c|}
\hline 항 목 & 값 \\
\hline 설치된 $\mathrm{AP}$ 수 & 4 대 \\
\hline $\mathrm{AP}$ 간 거리 & $5 \mathrm{~m}$ \\
\hline $\mathrm{AP}$ 와 단말의 거리 & $1 \mathrm{~m}$ \\
\hline 단말의 수신 파워 & $-35 \mathrm{dBm}$ \\
\hline 전송 표준 & $802.11 \mathrm{~b} / \mathrm{g} / \mathrm{n}$ \\
\hline 측정 시간 & 5 분 \\
\hline 측정 값 & 평균치 \\
\hline
\end{tabular}

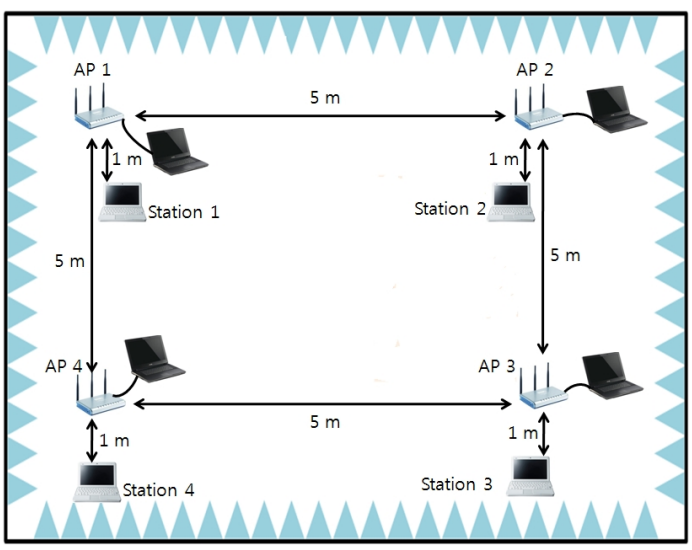

그림 5. 전자파 반무반사실 실험

Fig. 5. Experiment in the semi-anechonic chamber.

반사실에서 실험을 수행하였다. 전자파 반무반사실 에서의 실험 개요를 표 3 에 나타내었다.

그림 5 는 전자파 반무반사실의 실험 구성도를 나 타내고 있으며, 그림과 같이 $\mathrm{AP}$ 와 단말기의 위치를 고정시킨 후, $\mathrm{AP} 1 \sim \mathrm{AP} 4$ 의 채널 설정을 변화시켜 이 에 따른 단말 1 4의 전송 속도를 합산하여 총 전송 속도로 측정하였다.

총 전송 속도 측정은 무선 랜의 표준 $11 \mathrm{~b}, 11 \mathrm{~g}$, $11 n$ 에 따라 반복하였으며, 각 채널 조합과 표준에 따 른 총 전송 속도를 표 4와 그림 6에 나타내었다.

전자파 반무반사실의 실험 결과, 주파수 중첩이 적은 채널 조합의 순서, $(1,5,9,13)>(1,6,11,6)>$ $(1,5,6,11)>(1,1,1,1)$ 의 순으로 높은 전송 속도가 측정되었으며, 본 논문에서 제시한 채널 조합 $(1,5$, $9,13)$ 은 기존의 채널 조합 $(1,6,11)$ 과 비교하여 $11 \mathrm{~b}$, $11 \mathrm{~g}, 11 \mathrm{n}$ 표준에 따라 각각 $52.11 \%, 32.45 \%, 40.71$
표 4. 채널 조합에 따른 총 전송 속도 비교

Table 4. Comparison of total throughput according to channelling.

\begin{tabular}{|c|c|c|c|}
\hline \multirow{2}{*}{ 채널 조합 } & \multicolumn{3}{|c|}{ 총 전송 속도(Mbps) } \\
\cline { 2 - 4 } & $11 \mathrm{~b}$ & $11 \mathrm{~g}$ & $11 \mathrm{n}$ \\
\hline $1,5,9,13$ & 26.59 & 134.45 & 162.45 \\
\hline $1,6,11,6$ & 17.48 & 101.45 & 115.45 \\
\hline $1,5,6,11$ & 8.02 & 38.86 & 90.35 \\
\hline $1,1,1,1$ & 2.95 & 7.03 & 37.07 \\
\hline
\end{tabular}

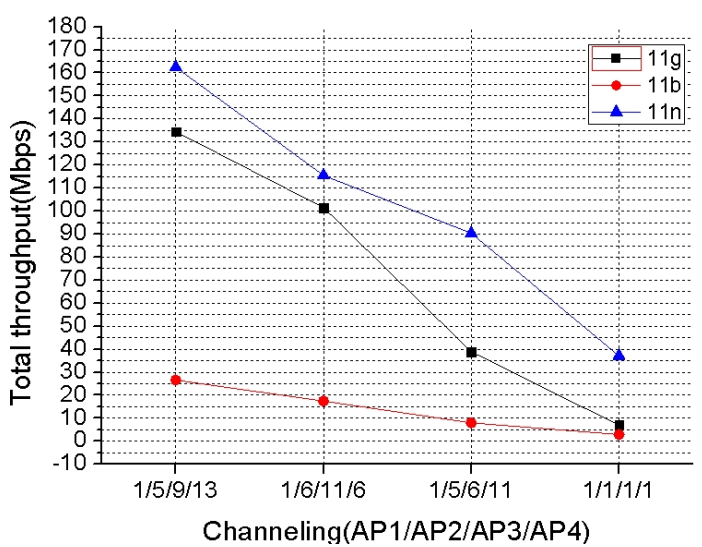

그림 6. 채널 조합에 따른 총 전송 속도 비교

Fig. 6. Comparison of total throughput according to channelling.

$\%$ 증가된 전송 속도가 측정되었다.

\section{3-2 AP 밀집도별 전송 속도 측정}

여기에서는, 특정 공간에 설치된 $\mathrm{AP}$ 의 수에 따른 전송 속도를 비교하기 위해 대강당의 실험 장소를 선정하여 설치 $\mathrm{AP}$ 의 수 $20,12,8$ 대에 따른 전송 속 도를 측정하였다.

이때, 각 $\mathrm{AP}$ 의 설정된 채널 조합은 $1,5,9,13$ 으로 고정하였으며, 각 $\mathrm{AP}$ 간의 고도차 및 장애물 등, 전 자파 반무반사실에 비해 추가적인 전송 속도 저하 요인이 발생하는 보다 실제와 가까운 환경이라 할 수 있다. 대강당에서의 실험 개요를 표 5 와 같이 요 약하였다.

그림 7과 같이 대강당의 실험은 $802.11 \mathrm{~g}$ 의 표준을 설정하고 대강당 내에 균일한 $\mathrm{AP}$ 의 분포를 갖도록 각 설치 $\mathrm{AP}$ 의 수에 따른 동일한 $\mathrm{AP}$ 간 이격 거리를 
THE JOURNAL OF KOREAN INSTITUTE OF ELECTROMAGNETIC ENGINEERING AND SCIENCE. vol. 23, no. 5, May 2012.

표 5. 대강당 실험

Table 5. Experiment in main auditorium.

\begin{tabular}{|c|c|}
\hline 항 목 & 값 \\
\hline 설치된 $\mathrm{AP}$ 수 & $8 / 12 / 20$ 대 \\
\hline $\mathrm{AP}$ 간 거리 & $4 \sim 7 \mathrm{~m}$ \\
\hline $\mathrm{AP}$ 와 단말의 거리 & $1 \sim 4 \mathrm{~m}$ \\
\hline 단말의 수신 파워 & $-65 \sim-55 \mathrm{dBm}$ \\
\hline 전송 표준 & $802.11 \mathrm{~g}$ \\
\hline 채널 조합 & $1,5,9,13$ \\
\hline 측정 시간 & 5 분 \\
\hline 측정 값 & 평균치 \\
\hline \multicolumn{2}{|c}{} \\
\hline
\end{tabular}

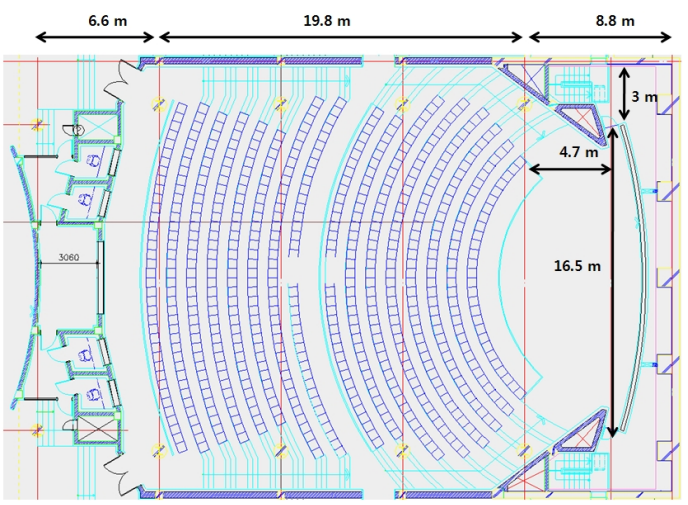

그림 7. 대강당 실험

Fig. 7. Experiment in main auditorium.

설정하여 위치시킨다.

전송 속도 측정에 있어, $\mathrm{AP}$ 밀집도를 나타내는 설 치 $\mathrm{AP}$ 수가 증가함에 따라 합산해야 하는 단말의 수 또한 증가하게 되어 결국 총 전송 속도의 증가 요인 이 발생한다. 동시에 $\mathrm{AP}$ 의 수가 증가하면 발생하는 간섭 또한 증가하게 되어 총 전송 저하의 요인이 또 한 발생한다. 즉, 설치 $\mathrm{AP}$ 의 밀집도 변화에 따라 총 전송 속도에 영향을 미치는 증가 요인과 저하 요인 에 대한 영향력을 비교하고자 한다.

대강당에서 설치한 $\mathrm{AP}$ 의 수를 $8 / 12 / 20$ 대로 변화 시킨 밀집도에 대한 전송 속도를 표 6과 그림 8에 나 타내었다.

$\mathrm{AP}$ 의 밀집도에 따른 전송 속도 측정 결과, 밀집도 가 낮은 순으로 $(8>12>20)$ 높은 총 전송 속도가 측 정되었다. 즉, 일반적으로 $\mathrm{AP}$ 간 간섭이 적은 경우 에서는 설치 $\mathrm{AP}$ 수 증가를 통해 총 전송 속도의 향
표 6. 밀집도에 따른 총 전송 속도 비교

Table 4. Comparison of total throughput according to density of AP.

\begin{tabular}{|c|c|}
\hline $\mathrm{AP}$ 수 & 총 전송 속도 \\
\hline 8 대 & 83.436 \\
\hline 12 대 & 31.470 \\
\hline 20 대 & 21.791 \\
\hline
\end{tabular}

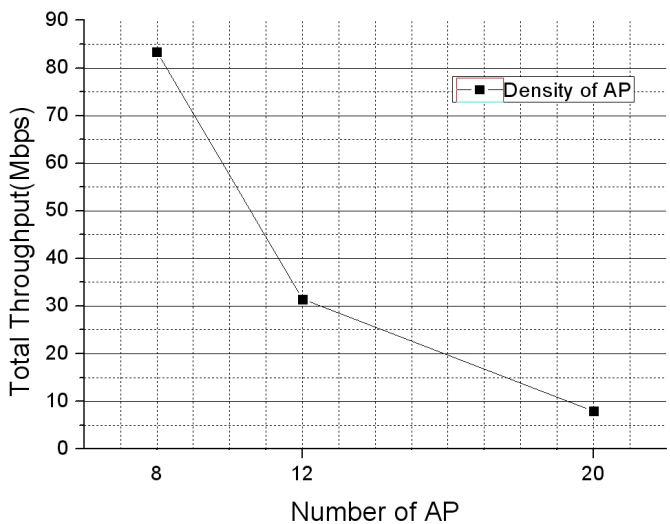

그림 8. 밀집도에 따른 총 전송 속도 비교

Fig. 8. Comparison of total throughput according to density of AP.

상을 기대할 수 있으나, 설치 $\mathrm{AP}$ 의 수와 전송 속도 는 반드시 비례하지 않고 밀집도가 증가할수록 오히 려 간섭이 증가하여 총 전송 속도의 저하를 유발할 수도 있음을 확인하였다.

\section{IV. 결 론}

본 논문은 최근 무선 랜의 사용이 급증함에 따라 무선 랜 상호간의 간섭으로 인한 전송 속도 저하 현 상이 예상되는 상황에서, 실제 다수 무선 랜이 사용 되는 곳의 전파 환경을 측정하여 기존의 $\mathrm{AP}$ 에 선택 된 채널 조합의 문제점을 파악하고, 보다 효율적인 채널 조합을 제시하였다. 또한, 실험을 통해 제시한 채널 조합의 효율성을 확인하였으며, 특정 공간에 설치된 $\mathrm{AP}$ 가 증가할수록 간섭현상이 심화되어 전송 속도의 저하가 발생함을 확인하였다.

따라서, 무선 랜의 전송 속도 개선을 위해 $\mathrm{AP}$ 의 채널 선택시 $1,5,9,13$ 의 채널 조합 설정을 권고함 과 동시에 특정 공간에서 설치 가능한 $\mathrm{AP}$ 의 수를 제 
한하는 것이 요구된다. 더불어, 설치 가능한 적정 $\mathrm{AP}$ 의 수를 도출하기 위해 안정된 단말기의 전송 속 도를 보장하는 $\mathrm{AP}$ 상호간에 적정 이격 거리에 관한 연구가 수행되어야 할 것이다.

\section{참 고 문 헌}

[1] 한국전자통신연구원, "안전한 전자파 환경조성 에 관한 연구", 방송통신위원회, pp. 195-200, 2010 년 12월.

[2] Jia-Liang Lu, Fabrice Valois B. Widrow, and S. D. Stearns, "Performance evaluation of 802.11 WLAN in a real indoor environment", Wireless and Mobile Computing Networking and Communications, IEEE International Conference, pp. 140-147, Jun. 2006.

[3] S. Kawade, T. G. Hodgkinson, and V. Abhayawardhana, "Interference analysis of $802.11 \mathrm{~b}$ and $802.11 \mathrm{~g}$ wireless systems", Vehicular Technology Conference

\section{심 용 섭}

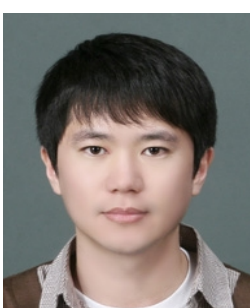

2005년 2월: 공주대학교 전기전자 정보공학과 (공학사)

2010년 2월: 공주대학교 정보통신 공학과 (공학석사)

2010년 9월 현재: 한국전자통신연 구원 위촉연구원

2011년 3월 현재: 공주대학교 정 보통신공학과 박사과정

[주 관심분야] RF 시스템, 전파 간섭, $\mathrm{EMC}$
VTC-2007 Fall, IEEE 66th, pp. 574-586, Sep. 2007. [4] 박진아, 박승근, "2.4 GHz ISM 대역에서 IEEE $802.11 \mathrm{~b}$ 기반의 무선 랜과 $\mathrm{RF}$ 전구의 전파간섭 분석", 전자통신동향분석, 21(6), pp. 202-211, 2006 년 12월.

[5] 김채영, 박정근, 박승근, "DSSS 방식용 무선 LAN 에 대한 전파 잡음의 영향", 한국전자파학회논문 지, 19(6), pp. 630-639, 2008년 6월.

[6] Jin-A Park, Seung-Keun, Park, Pyung-Dong Cho, and Kyoung-Rok Cho, "Analysis of spectrum channel assignment for IEEE 802.11b wireless LAN", Wireless Personal Multimedia Communications, vol. 2002, no. 3, pp.1073-1077, 2002.

[7] 김수형, "공공장소서 유독 느린 '와이파이' $\cdots$ 이 유 있었네", SBS NEWS, 2011년 2월.

[8] http://www.netstumbler.com

박 승 근

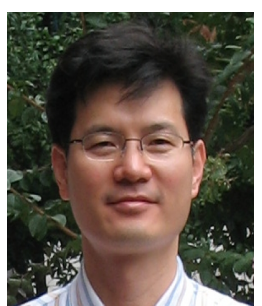

1991년 2월: 고려대학교 응용통계 공학과 (이학사) 1993년 8월: 고려대학교 응용통계 공학과 (이학석사)

2004년 2월: 충북대학교 정보통신 공학과 (공학박사)

1993년 8월 현재: 한국전자통신연

구원 책임연구원

[주 관심분야] 디지털 통신, 스펙트럼공학

\section{전 상 봉}

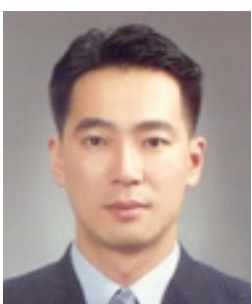

2001년 2월: 영남대학교 전자공학 과 (공학사)

2003년 2월: 영남대학교 전자공학 과 (공학석사)

2007년 8월: 영남대학교 전자공학 과 (공학박사)

2008년 6월 2010년 9월: 한국전파 진흥협회 $\mathrm{EMC}$ 기술지원센터

2010년 10월 현재: 한국전자통신연구원 선임연구원 [주 관심분야] $\mathrm{EMI} / \mathrm{EMC}$ 측정 및 대책기술, 전자파수치해 석 